
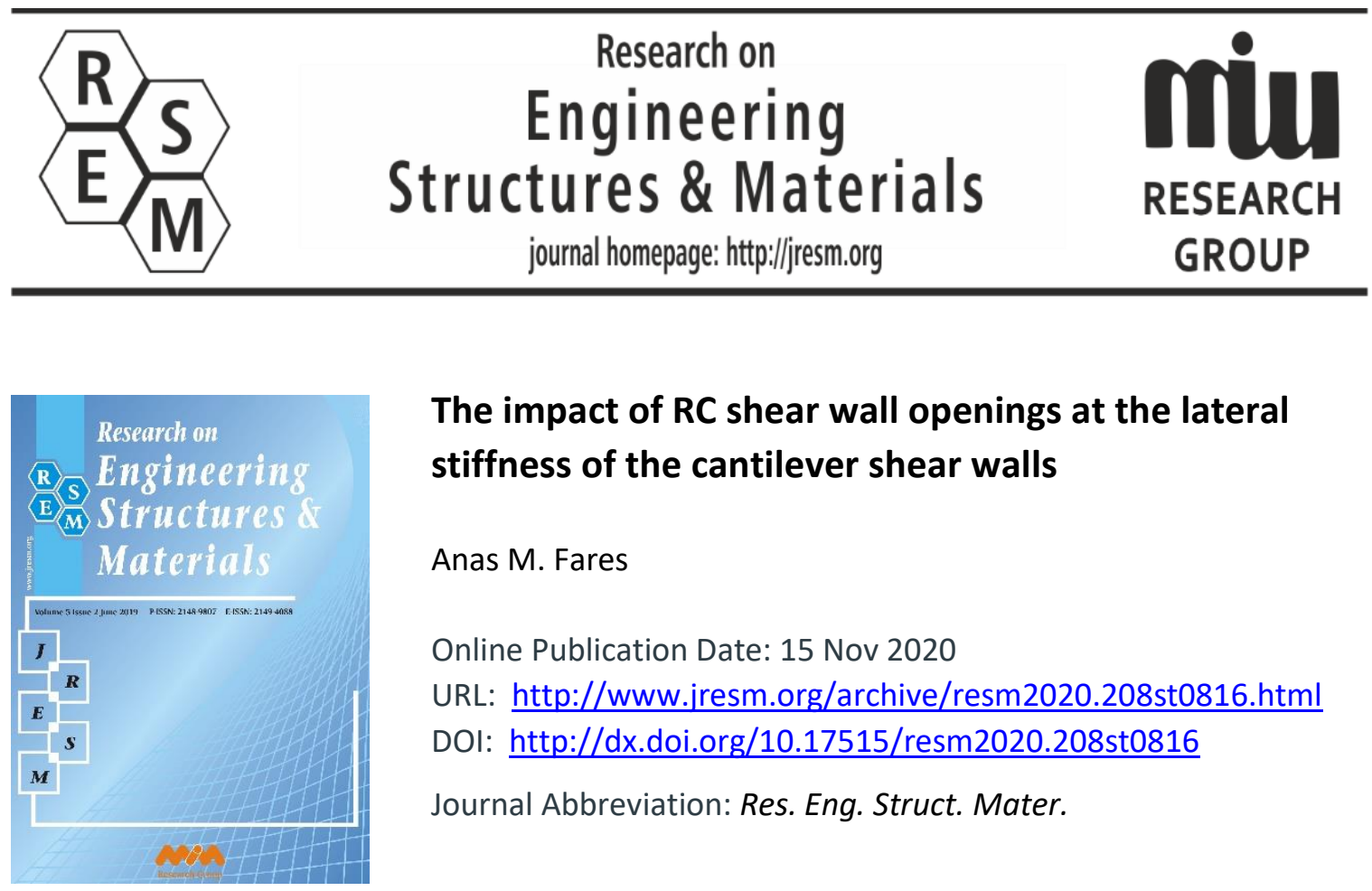

\title{
The impact of RC shear wall openings at the lateral stiffness of the cantilever shear walls
}

\author{
Anas M. Fares
}

Online Publication Date: 15 Nov 2020

URL: http://www.jresm.org/archive/resm2020.208st0816.html

DOI: http://dx.doi.org/10.17515/resm2020.208st0816

Journal Abbreviation: Res. Eng. Struct. Mater.

\section{To cite this article}

Fares A M. The impact of RC shear wall openings at the lateral stiffness of the cantilever shear walls. Res. Eng. Struct. Mater., 2021; 7(1): 51-63.

\section{Disclaimer}

All the opinions and statements expressed in the papers are on the responsibility of author(s) and are not to be regarded as those of the journal of Research on Engineering Structures and Materials (RESM) organization or related parties. The publishers make no warranty, explicit or implied, or make any representation with respect to the contents of any article will be complete or accurate or up to date. The accuracy of any instructions, equations, or other information should be independently verified. The publisher and related parties shall not be liable for any loss, actions, claims, proceedings, demand or costs or damages whatsoever or howsoever caused arising directly or indirectly in connection with use of the information given in the journal or related means.

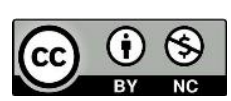

Published articles are freely available to users under the terms of Creative Commons Attribution - NonCommercial 4.0 International Public License, as currently displayed at here (the "CC BY - NC"). 


\section{Research on Engineering Structures \& Materials}

journal homepage: http://jresm.org

Research Article

\section{The impact of RC shear wall openings at the lateral stiffness of the cantilever shear walls}

Anas M. Fares

Department of Civil Engineering, Necmettin Erbakan University, Konya, Turkey

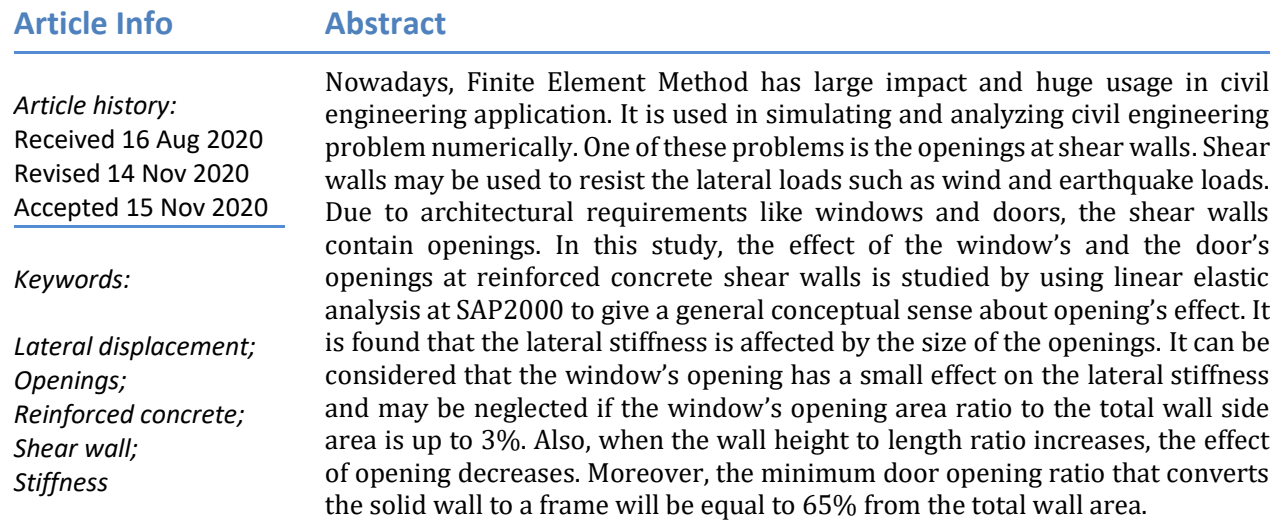

(C) 2021 MIM Research Group. All rights reserved.

\section{Introduction}

Buildings should have sufficient capacity to resist any lateral loads such as earthquake and wind forces. Different lateral resisting systems are used to increase the stiffness capacity; the most common lateral bracing system in the buildings is the reinforced concrete shear wall system. This system has many forms depending on the position and function of walls like core walls, coupled walls, and planar walls. According to Bungale [1], this system is the most appropriate in moderate sized building up to 20 floors. Shear wall system is not preferred in the case of tall buildings, because this system will use a lot of concrete and reinforced steel bars when comparing to other lateral bracing systems like moment resisting frames. The shear wall system is not also preferred in the open spaced structures due to architectural functions.

Due to small drift between floors and good stability in buildings, which will make the buildings more rigid, shear walls offer good performance in resisting lateral loads. Although the internal base shear force in this type of construction is generally more than that of other resisting systems, the capacity of the shear wall system can accept this large force induced by earthquakes. Windows and doors are required to be existed at shear walls due to architectural functions, these openings cause a variation in relative stiffness of wall with openings that extend from that of a solid wall to that of a flexible frame.

The designers are generally ignored the effect of these openings in walls to simplify both modeling and analyzing the structures by using finite element programs. Such choice of neglecting these openings may produce unreal results in seismic design of buildings. So, it

Corresponding author: anas fares76@yahoo.com

orcid.org/0000-0003-2804-7364

DOI: http://dx.doi.org/10.17515/resm2020.208st0816

Res. Eng. Struct. Mat. Vol. 7 Iss. 1 (2021) 51-63 
is thus of prime important to quantify the effect of these openings on the lateral stiffness of buildings.

To conduct this study a literature review is done so as to understand analytical methods or experimental results. The commercial program SAP2000 based on using finite element method is then chosen to be the calculation tool. the linear elastic analysis is performed to give a general conceptual sense about opening's effect. The shear walls are modeled as 2D thin-shell elements. Lateral concentrated loads at the top of shear walls are assigned. The effect of wall height $(\mathrm{H})$ to the wall length $(\mathrm{B})$ is also studied when squared central window openings are existed.

The general objectives of this study are as the following:

- Investigation the effect of the opening's sizes on the lateral stiffness of reinforced concrete shear walls.

- Identifying the maximum ratios of square window openings in the reinforced concrete shear walls to the size of the side wall that can be neglected in modeling the structures for the purpose of simplification.

- Recognizing the minimum opening ratio that converts the behavior of a solid wall to that of a frame, in order to help the designers to make their models as simple and safe as possible.

- To investigate the effect of wall aspect ratio $(\mathrm{H} / \mathrm{B})$, wall height $(\mathrm{H})$ to wall length (B), on the stiffness of concrete shear walls with different patterns of openings.

\section{Literature Review}

For many years, the performance of shear wall system has been investigated. The effect of opening size, openings location, openings arrangement and depth have been studied. This section gives brief information collected from many papers and studies, dealing with the behavior of reinforced concrete shear walls with and without openings. Most of these papers are related to experimental and analytical studies of the capacity of shear walls to resist dynamic loads.

Aghayari et al. [2] studied the behavior of coupled shear wall system because most structural design codes have no clear seismic design consideration for base shear, lateral stiffness and period for this system as Aghayari et al. claimed. Aghayari et al. used finite element models built in ANSYS and divided into two categories. First category is the onefloor, two-floor, and three-floor 3D solid models with two-way slabs. The second category is one-floor individual wall with $5 \mathrm{~m}$ length, $3.5 \mathrm{~m}$ height, and $0.15 \mathrm{~m}$ thickness with different central window opening ratios. As a result of their work, corrective coefficients were presented according to the numerical results. They noticed that the empirical formulas in ASCE code for period estimation may not be reliable for real design yet in the case of coupled walls structures. They also noticed that the stiffness of concrete shear walls and fundamental period both are affected by the opening ratio and it is better to use some other structural parameters like relative wall area and opening ratio in the code equations for fundamental period calculations to be more accurate. Based on this work, Aghayari et al. proposed a modification factor to consider the effect of opening ratio on both the lateral stiffness and the fundamental period of individual coupled wall. Multiplication of this factor by the ASCE code empirical formula of period produces more accurate and reliable value.

Sharma et al. [3] analyzed 30-storey building with different opening sizes and shapes at the shear walls, they found that the size of these openings affects the lateral deflection of the building, and the shape of the opening will also affect the drift of the studied building. 
The openings produce high local vertical stress and shear strain concentrations around the opening's corners.

Hsiao [4] proposed a new hand calculations method to estimate the rigidity and the lateral deflection of shear walls with openings with an acceptable difference between finite element method and his hand calculations method results. Hsiao method allows the piers of walls at the top to rotate. Hsiao method is divided into 9 steps, where the wall is subdivided into pieces and the equivalent frame method is used to find the deflection of each piece, and then the deflections are combined by a sort of superposition. Hsiao made the following assumptions while deriving his method: (1) The wall is in one floor only (2) A single opening or one layer of multiple openings with the same height elevation (3) The analysis is restricted to linear elastic (4) The foundations are Rigid and no wall deflection due to foundation rotation.

Harini et al. [5] applied numerical finite element method on 7 floors frame-shear wall buildings with openings using linear elastic response spectrum analysis. Harini et al. found that staggered openings exhibited a higher value of period when compared to vertically aligned openings. They also noticed that staggered openings can perform better during seismic action, because cracks propagation in staggered openings is smaller than vertically aligned openings and they will appear at late stage of earthquake.

Sharmin et al. [6] studied the effect of openings in concrete shear walls on the seismic response of structure. They conducted a finite element study by using ETABS program with 6 floors frame-shear wall building by using equivalent static method of earthquake loads. They noticed that the seismic response of the studied structure affected by the size and the location of the opening. the top lateral drift of the building can be reduced thickening the element in the model around the opening of shear wall.

Abbas M [7] conducted study about shear wall with openings by using brick elements. he found that the size of opening play major role in increasing the lateral drift of walls.

Neuenhofer [8] evaluated the accuracy of a simplified hand method proposed by Brandow et al.1997 and Lindeburg at al. 2001 to calculate the lateral deflection of cantilever concrete shear walls with openings due to flexural and shear deformation, where Neuenhofer claimed that this method is used in several design guidelines. Neuenhofer compared these hand method and numerical finite element algorithm on MATLAB at two examples, one for window opening and another for door opening. Neuenhofer found that the lateral stiffness is strongly affected by the vertical location of the opening in the walls, and the hand calculation method doesn't consider this factor. Neuenhofer conducted two parametric studies to find the percentage of error between the hand method and numerical method one for window opening and another for door opening by fixing the wall geometry and change the vertical location of opening. Neuenhofer noticed that the error between hand calculation method and finite element method increases when the vertical location of the opening increase and this error also increases when the opening ratio increases. Thus, Neuenhofer concluded that the Brandow et al. and Lindeburg at al. simplified hand method should be removed from the design guidelines and documents for practicing structural engineering as he claimed.

Kim et al. [9] try to investigate and found a method that may be used in analyzing shear walls with openings. they propose this method by using super elements to model the shear wall.

Balkaya et al. [10] compared the codes formula UBC-97, and Turkish seismic code-98 for estimating the fundamental period of reinforced concrete multi-story shear wall with no opening structures and they found that the equations yielded inaccurate results. They also studied the effect of openings on the lateral stiffness of structure. They performed a 
numerical linear elastic modal analysis study using ETABS version 7.22 with 2D shell element on 80 different shear wall buildings in their local region with different openings sizes and locations by using tunnel form techniques with no beams or columns and only using cast in-place walls and slabs with almost the same thickness. In their study, they recommended to use the slab as it is without making any rigid or semi rigid diaphragm assumption in the models. The 80 different buildings were divided into two cases; squared ones with the building long side divided by the short side is less than 1.5, otherwise the buildings are considered as rectangular ones. The final fundamental period results are taken from the first mode of modal analysis. Their proposed equation has a set of factors which affect the period and all of these parameters have numerical coefficients found by non-linear regression. They concluded to use this formula to improve the accuracy when calculate the fundamental period of such structures. Balkaya et al. didn't make any restriction when using their formula like restriction in the number of floors, restriction in the location and sizes of the openings. They also didn't consider the soil-structure interaction in their study. They advised that opening size has to be used in the calculation of the fundamental period and the lateral stiffness, because it plays a major role in the value of drift of structure.

J'aidi [11] studied the rigidity of concrete shear walls with and without openings. He carried out a numerical study using SAP90 to get the results. J'aidi concluded that the rigidity of the solid concrete walls without openings is a function of the wall aspect ratio (height/length) being the most dominated factor, so the walls with the same aspect ratio, same material, and same thickness will have the same rigidity value. J'aidi found numerically that the shear deformation can be neglected when the wall aspect ratio equals to 4 . He suggested two patterns for both window and door openings, where the window opening patterns weren't at the center of a studied $3 \times 4 \mathrm{~m}$ wall. As a result of his study, the small window opening which captured about $2 \%$ of the wall area can be neglected, because this percentage of opening reduces the rigidity of the solid wall to about $90 \%$, while $12 \%$ window opening area reduces the rigidity to about $50 \%$.

Qaqish et al. [12] investigated the effect of small openings on the behavior of shear walls. They found that when increasing the size of openings, the effect on lateral stiffness will appears clearly.

Mays et al. [13] described a proposed method for the derivation of quasi-static elastic/plastic resistance functions for reinforced concrete wall panels with door and window openings based upon finite element analysis and yield-line theory. This approach is compared with the results of tests on model wall panels. This work has demonstrated that the total ultimate resistance of a panel decreased by up to $60 \%$ for openings representing $20 \%$ of the panel area. The theory predicted that up to $37 \%$ of the residual capacity could then be lost by the incorporation of blast-resistant openings. Stiffening the edges of openings by placing reinforcement equal in quantity to that which has been interrupted adjacent to the opening appears to be beneficial.

Yanez et al. [14] conducted a study on the effect of square opening at concrete walls on the seismic behavior. different sizes and arrangements of openings studied under reversed cyclic loading. It was concluded that the stiffness of walls is dependent on the size of the openings not on their horizontal locations. It was suggested that if the opening area to the side wall area is up to $10 \%$, the effect on lateral stiffness can be neglected.

Lin et al. [15] studied the ultimate strength of concrete walls with openings under lateral load by conducting a finite element analysis and experimental study. The experimental tests conducted by different wall samples with different sizes of opening and multi patterns of reinforcing around the opening. The test results indicated that the shear strength contributed by diagonal reinforcement around opening reached $40 \%$ of its yield 
strength, while the shear strength contributed by rectangular arrangement reached $20 \%$ of its yield strength. The stiffness of walls also affected by the depth of opening.

\section{Central Window Opening and Opening Ratio $\left(R_{0}\right)$ : Analyzing and results}

The openings at shear walls in the reality are either doors or windows. In this section, the effect of central window opening on the wall stiffness will be studied because these openings cause a variation in lateral stiffness that extends from that of a solid wall to that of a frame as shown in Fig.1.

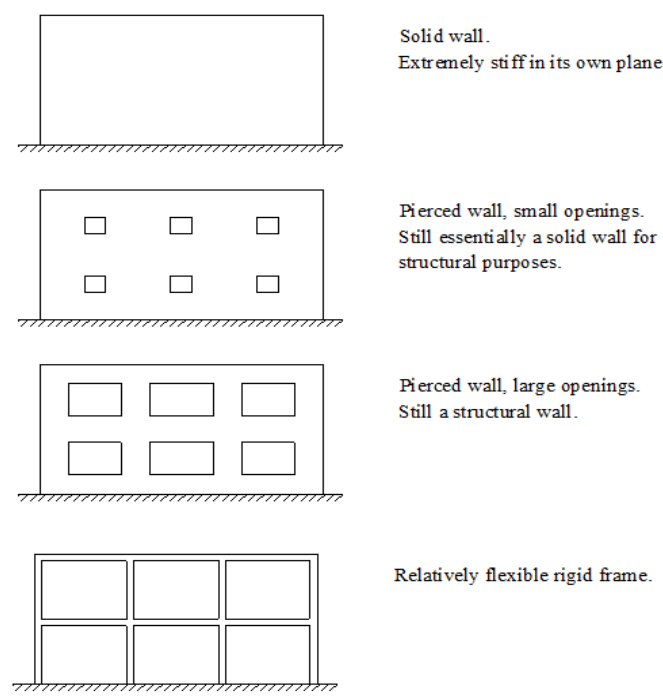

Fig. 1 Transition in a monolithic planer construction, from a solid wall to a flexible, moment resisting frame [16]

The openings at walls affect the total stiffness of the structure and may reduce it which leads to a decrease in the lateral stiffness of structure. In the following study, the wall thickness, aspect ratio (H/B), and wall concrete material are assumed to be fixed and the wall opening ratio is the only parameter to be varied.

A $3 \times 3 \mathrm{~m} 2 \mathrm{D}$ planer cantilever wall is modeled with concrete compressive strength $\mathrm{f}_{\mathrm{c}}{ }_{\mathrm{c}}$ equals to $24 \mathrm{MPa}$, the thickness of the wall equals to $0.2 \mathrm{~m}$, and top shear load equals to $1000 \mathrm{kN}$. These parameters are to evaluate the effect of different central window and door openings in the next sections. Fig. 2 shows model number C-W12 with dimensions as modeled at SAP2000. A deflection of each case is tabulated then the relationship between opening ratios in the wall and the corresponding change in stiffness are shown in graphs.

17 central squared window openings of varying sizes are suggested. In this section the largest ratio of central window opening in a wall whose effect on the lateral stiffness is small and can be neglected will be identified. The results of the average lateral deflection of the top points $(\Delta)$, the lateral stiffness $(\mathrm{K})$, and the stiffness ratio ( $\left.\mathrm{R}_{\mathrm{S}}\right)$ are tabulated in Table 1.

For the naming of the models, $\mathrm{C}$ refers to the concrete wall and $\mathrm{W}$ refers to window opening. The stiffness ratio (Rs) is defined as the ratio of the lateral stiffness of a wall with opening divided by the lateral stiffness of the same wall without openings. The opening ratio $\left(\mathrm{R}_{0}\right)$ represents the opening area in the wall divided by the total wall side area. The lateral stiffness $(\mathrm{K})$ is founded by dividing the lateral load $(\mathrm{P})$ onto the average lateral deflection of the top points $(\Delta)$ for each case. 


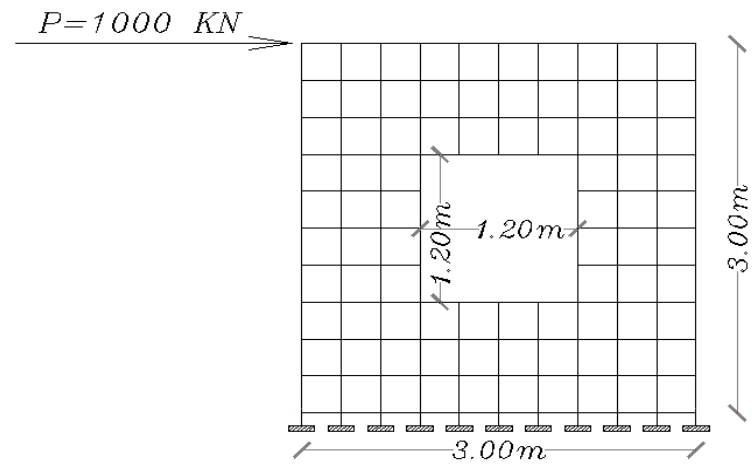

Fig. 2 C-W12 3×3m cantilever wall model with central window opening

Table 1 . Results of window opening models with a $3 \times 3 \mathrm{~m}$ wall

\begin{tabular}{cccccc}
\hline $\begin{array}{c}\text { Model } \\
\text { number }\end{array}$ & $\begin{array}{c}\text { Opening size } \\
(\mathrm{m})\end{array}$ & $\begin{array}{c}\text { Opening } \\
\text { ratio, } \mathrm{R}_{\mathrm{o}} \\
(\%)\end{array}$ & $\begin{array}{c}\text { Top } \\
\text { displacement, } \\
(\mathrm{mm})\end{array}$ & $\begin{array}{c}\text { Stiffness, K } \\
\left(10^{4} \mathrm{kN} / \mathrm{m}\right)\end{array}$ & $\begin{array}{c}\text { Stiffness } \\
\text { ratio, } \mathrm{R}_{\mathrm{s}} \\
(\%)\end{array}$ \\
\hline C-W0 & 0.00 & 0.00 & 1.47 & 67.89 & 100 \\
C-W3 & $0.3 \times 0.3$ & 1.00 & 1.52 & 65.79 & 96.90 \\
C-W4 & $0.4 \times 0.4$ & 1.87 & 1.52 & 65.70 & 96.78 \\
C-W5 & $0.5 \times 0.5$ & 2.78 & 1.55 & 64.52 & 95.03 \\
C-W6 & $0.6 \times 0.6$ & 4.00 & 1.66 & 60.24 & 88.73 \\
C-W7 & $0.7 \times 0.7$ & 5.44 & 1.76 & 56.81 & 83.69 \\
C-W8 & $0.8 \times 0.8$ & 7.11 & 1.86 & 53.76 & 79.19 \\
C-W9 & $0.9 \times 0.9$ & 9.00 & 2.00 & 50.00 & 73.65 \\
C-W10 & $1 \times 1$ & 11.11 & 2.21 & 45.24 & 66.65 \\
C-W11 & $1.1 \times 1.1$ & 13.44 & 2.54 & 39.37 & 57.99 \\
C-W12 & $1.2 \times 1.2$ & 16.00 & 2.84 & 35.21 & 51.87 \\
C-W13 & $1.3 \times 1.3$ & 18.78 & 3.28 & 30.49 & 44.91 \\
C-W14 & $1.4 \times 1.4$ & 21.78 & 3.90 & 25.64 & 37.77 \\
C-W15 & $1.5 \times 1.5$ & 25.00 & 4.66 & 21.45 & 31.61 \\
C-W16 & $1.6 \times 1.6$ & 28.44 & 5.66 & 17.66 & 26.02 \\
C-W17 & $1.7 \times 1.7$ & 32.11 & 7.16 & 13.96 & 20.57 \\
C-W18 & $1.8 \times 1.8$ & 36.00 & 9.05 & 11.05 & 16.27 \\
\hline
\end{tabular}

\subsection{Discussion of Results}

Fig. 3 shows the relationship between $R_{s}$ and $R_{o}$ as expected. Increasing the size of opening will decrease the stiffness of the wall. If $5 \%$ reduction in the wall lateral stiffness is considered negligible, then the opening area in the wall give such a reduction in stiffness equals $3 \%$ of the total wall side area. Thus, central window opening can be neglected in modeling the walls when its area ratio to total wall side area is up to $3 \%$. In the common practice the $3 \%$ opening area appears in the bathroom window openings. Typical squared window opening of size $1.30 \times 1.30 \mathrm{~m}$ which is commonly used in practice reduces the stiffness of $3 \times 3 \mathrm{~m}$ solid wall to about $50 \%$. The rapid drop in stiffness can be noticed when using large opening ratios. When the opening ratio is around $17 \%$ from the total wall area, the wall will lose $50 \%$ of it is stiffness. 


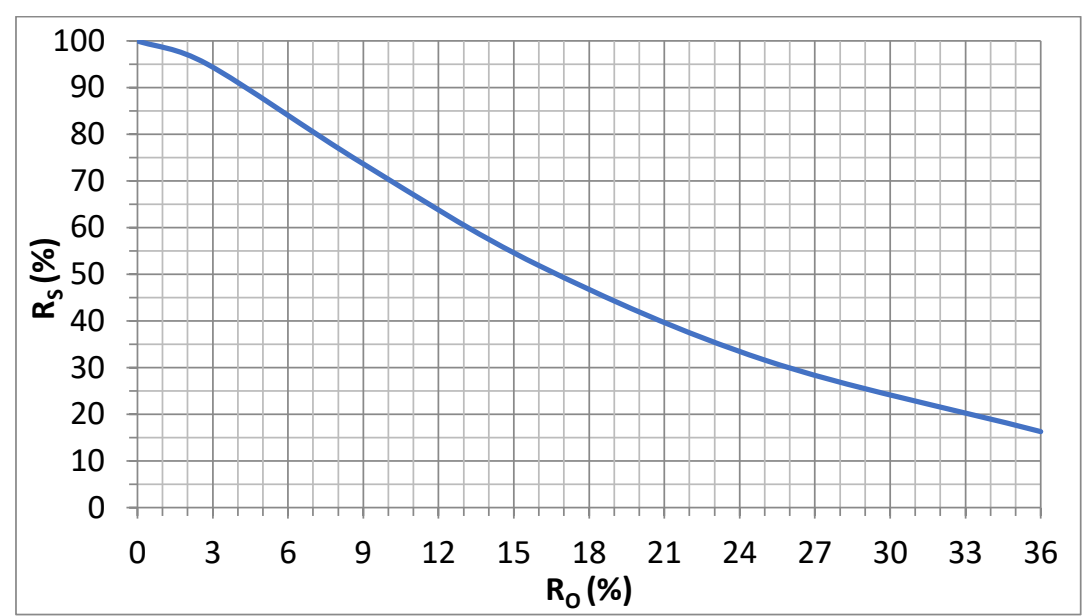

Fig. 3 Squared windows opening ratio versus stiffness ratio of $3 \times 3 \mathrm{~m}$ wall

\section{Effect of Wall (H/B) Ratio with Central Openings on The Lateral Displacement}

35 cases for the same previous wall length, thickness and material are taken to study the effect of wall height and multiple openings on the top lateral displacement. $1000 \mathrm{kN}$ lateral load is applied on the top of the wall at each floor level where floor height is assumed to be $3 \mathrm{~m}$, and then the results of top displacement $(\Delta)$, and displacement ratio $\left(R_{D}\right)$ which is defined as the ratio of the lateral top displacement of a wall with opening divided by the lateral displacement of the same wall without openings are tabulated in Table 2. For the naming of the models, $\mathrm{C}$-W refers to concrete wall and window opening respectively, then the first number and the second number refers to the opening ratio and $(\mathrm{H} / \mathrm{B})$ respectively. Fig 4 shows a schematic drawing for C-W12,2.

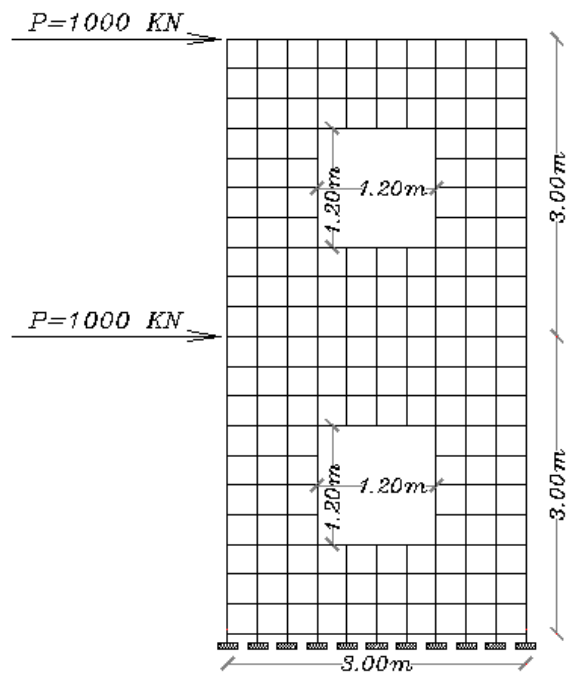

Fig. 4 C-W12,2 model with boundary conditions and applied lateral loads 
Table 2. lateral displacement results on different wall heights and central opening sizes

\begin{tabular}{|c|c|c|c|c|c|}
\hline $\begin{array}{c}\text { Model } \\
\text { number }\end{array}$ & $\begin{array}{l}\text { H/B } \\
\text { (m) }\end{array}$ & $\begin{array}{l}\text { Opening } \\
\text { size } \\
\text { (m) }\end{array}$ & $\begin{array}{c}\text { Total } \\
\text { opening } \\
\text { ratio, Ro } \\
(\%)\end{array}$ & $\begin{array}{c}\text { Top } \\
\text { displacement, } \\
\Delta(\mathrm{mm})\end{array}$ & $\begin{array}{c}\text { Displacement } \\
\text { Ratio, } \mathbf{R}_{\mathbf{D}}\end{array}$ \\
\hline C-W0,2 & 2 & 0.00 & 0.00 & 10.92 & 1.00 \\
\hline C-W3,2 & 2 & $0.3 \times 0.3$ & 1 & 11.00 & 1.01 \\
\hline C-W6,2 & 2 & $0.6 \times 0.6$ & 4 & 11.52 & 1.05 \\
\hline C-W9,2 & 2 & $0.9 \times 0.9$ & 9 & 12.60 & 1.15 \\
\hline C-W12,2 & 2 & $1.2 \times 1.2$ & 16 & 15.30 & 1.40 \\
\hline C-W15,2 & 2 & $1.5 \times 1.5$ & 25 & 21.21 & 1.94 \\
\hline C-W18,2 & 2 & $1.8 \times 1.8$ & 36 & 35.15 & 3.22 \\
\hline C-W0,3 & 3 & 0.00 & 0.00 & 42.67 & 1.00 \\
\hline C-W3,3 & 3 & $0.3 \times 0.3$ & 1 & 42.78 & 1.00 \\
\hline C-W6,3 & 3 & $0.6 \times 0.6$ & 4 & 43.86 & 1.03 \\
\hline C-W9,3 & 3 & $0.9 \times 0.9$ & 9 & 46.21 & 1.08 \\
\hline C-W12,3 & 3 & $1.2 \times 1.2$ & 16 & 52.22 & 1.22 \\
\hline C-W15,3 & 3 & $1.5 \times 1.5$ & 25 & 65.94 & 1.55 \\
\hline C-W18,3 & 3 & $1.8 \times 1.8$ & 36 & 95.93 & 2.25 \\
\hline C-W0,6 & 6 & 0.00 & 0.00 & 531.00 & 1.00 \\
\hline C-W3,6 & 6 & $0.3 \times 0.3$ & 1 & 532.30 & 1.00 \\
\hline C-W6,6 & 6 & $0.6 \times 0.6$ & 4 & 536.95 & 1.01 \\
\hline C-W9,6 & 6 & $0.9 \times 0.9$ & 9 & 548.85 & 1.03 \\
\hline C-W12,6 & 6 & $1.2 \times 1.2$ & 16 & 581.63 & 1.10 \\
\hline C-W15,6 & 6 & $1.5 \times 1.5$ & 25 & 654.95 & 1.23 \\
\hline C-W18,6 & 6 & $1.8 \times 1.8$ & 36 & 809.32 & 1.52 \\
\hline C-W0,9 & 9 & 0.00 & 0.00 & 2487.50 & 1.00 \\
\hline C-W3,9 & 9 & $0.3 \times 0.3$ & 1 & 2488.11 & 1.00 \\
\hline C-W6,9 & 9 & $0.6 \times 0.6$ & 4 & 2501.2 & 1.01 \\
\hline C-W9,9 & 9 & $0.9 \times 0.9$ & 9 & 2539.54 & 1.02 \\
\hline C-W12,9 & 9 & $1.2 \times 1.2$ & 16 & 2650.85 & 1.07 \\
\hline C-W15,9 & 9 & $1.5 \times 1.5$ & 25 & 2901.55 & 1.17 \\
\hline C-W18,9 & 9 & $1.8 \times 1.8$ & 36 & 3399.91 & 1.37 \\
\hline C-W0,12 & 12 & 0.00 & 0.00 & 7562.73 & 1.00 \\
\hline C-W3,12 & 12 & $0.3 \times 0.3$ & 1 & 7562.87 & 1.00 \\
\hline C-W6,12 & 12 & $0.6 \times 0.6$ & 4 & 7593.03 & 1.00 \\
\hline C-W9,12 & 12 & $0.9 \times 0.9$ & 9 & 7690.39 & 1.02 \\
\hline C-W12,12 & 12 & $1.2 \times 1.2$ & 16 & 7982.19 & 1.06 \\
\hline C-W15,12 & 12 & $1.5 \times 1.5$ & 25 & 8640.97 & 1.14 \\
\hline C-W18,12 & 12 & $1.8 \times 1.8$ & 36 & 9908.36 & 1.321 \\
\hline
\end{tabular}

\subsection{Discussion of Results}

Fig 5. shows the relationship between the displacement ratios versus opening ratios for different wall H/B ratio. From this figure, the increase in H/B shall reduce effect of openings. The reduction in $\mathrm{RD}$ will be in a rapid form when the wall aspect ratio is small, where the effect of shear deformation contribution is significant compared with large aspect ratio.

The effect for the same $R_{0}$ on the lateral displacement becomes smaller as the height of the building increases. This effect appears more clearly for low number of floors. The lateral deflection and the stiffness of the concrete shear wall with opening depend on the wall $\mathrm{H} / \mathrm{B}$ ratio. If $\mathrm{H} / \mathrm{B}$ increases, then the deflection mode becomes dominated by flexure. Thus, the 
area of the wall is not the dominant factor in the lateral deflection, but rather the moment of inertia. Reducing the central area of the wall by increasing the central $\mathrm{R}_{0}$ will reduce the wall moment of inertia by a small value, but it is reducing the shear area of the wall by large value. It can also be seen that $3 \% \mathrm{R}_{0}$ still gives negligible reduction in the lateral stiffness of walls with different $H$ /B ratios, where all values of $R_{D}$ are less than 1.05 for $H / B$ greater than 1.

To find out the maximum $\mathrm{R}_{0}$ that can be neglected, a threshold of $5 \%$ increase in RD will be accepted as a negligible difference. From Figure 3.9 the value of RO that can be neglected safely is $4.00 \%, 6.00 \%, 11.00 \%, 14.00 \%$ and $15.00 \%$ for $\mathrm{H} / \mathrm{B}$ equals to $2,3,6,9$ and 12 respectively.

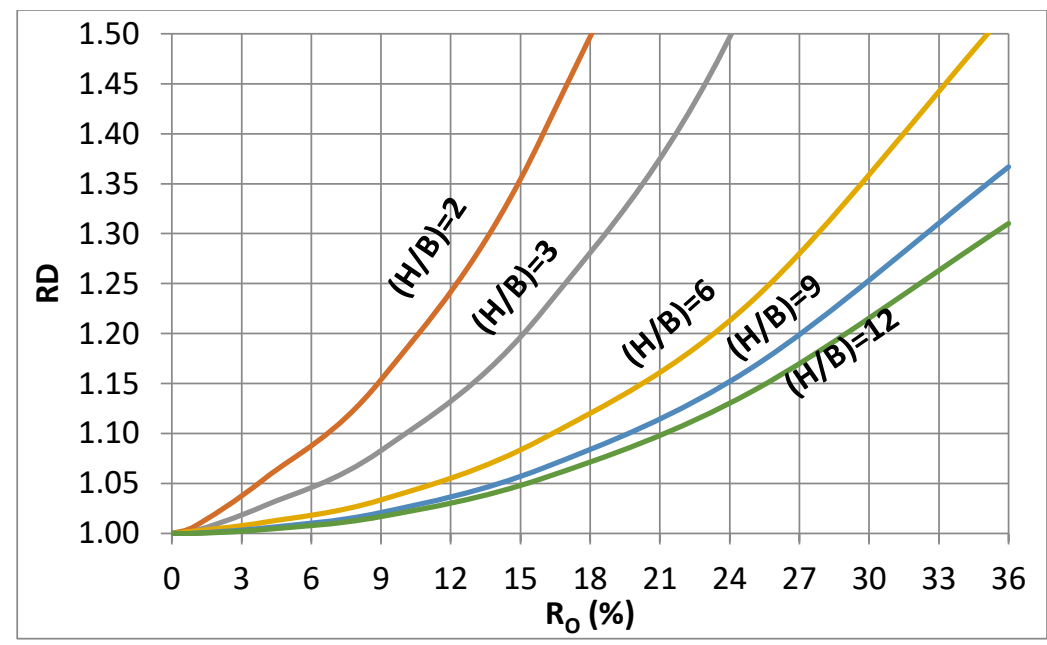

Fig. 5 Displacement ratio RD versus opening ratio RO for different floor heights in shear wall with multiple openings

Moreover, if the engineer models the wall with opening as a solid wall for simplification issues, then the result of the lateral displacement must be modified by using lateral displacement modifiers. For the common central window opening of $1.30 \times 1.30 \mathrm{~m}$, the top lateral displacement modifiers are 1.50, 1.30, 1.10, 1.09 and $1.07 \mathrm{for} \mathrm{H} / \mathrm{B}$ equals to 2, 3, 6, 9 and 12 respectively. Multiplying these values with the top lateral displacement of concrete shear walls with no openings will give the top lateral displacement of the walls with central $1.3 \times 1.30 \mathrm{~m}$ window opening.

\section{Door Opening: Analyzing and results}

In this section, the effect of door opening in a wall on the lateral stiffness will be studied using 4 door openings of varying sizes that are suggested as shown in Fig.7. This figure shows the wall model at the left and its equivalent frame model at the right with dimensions. These models will be named as C-D followed by the dimension of the opening, where $\mathrm{C}$ and $\mathrm{D}$ refer to concrete wall with door opening. 

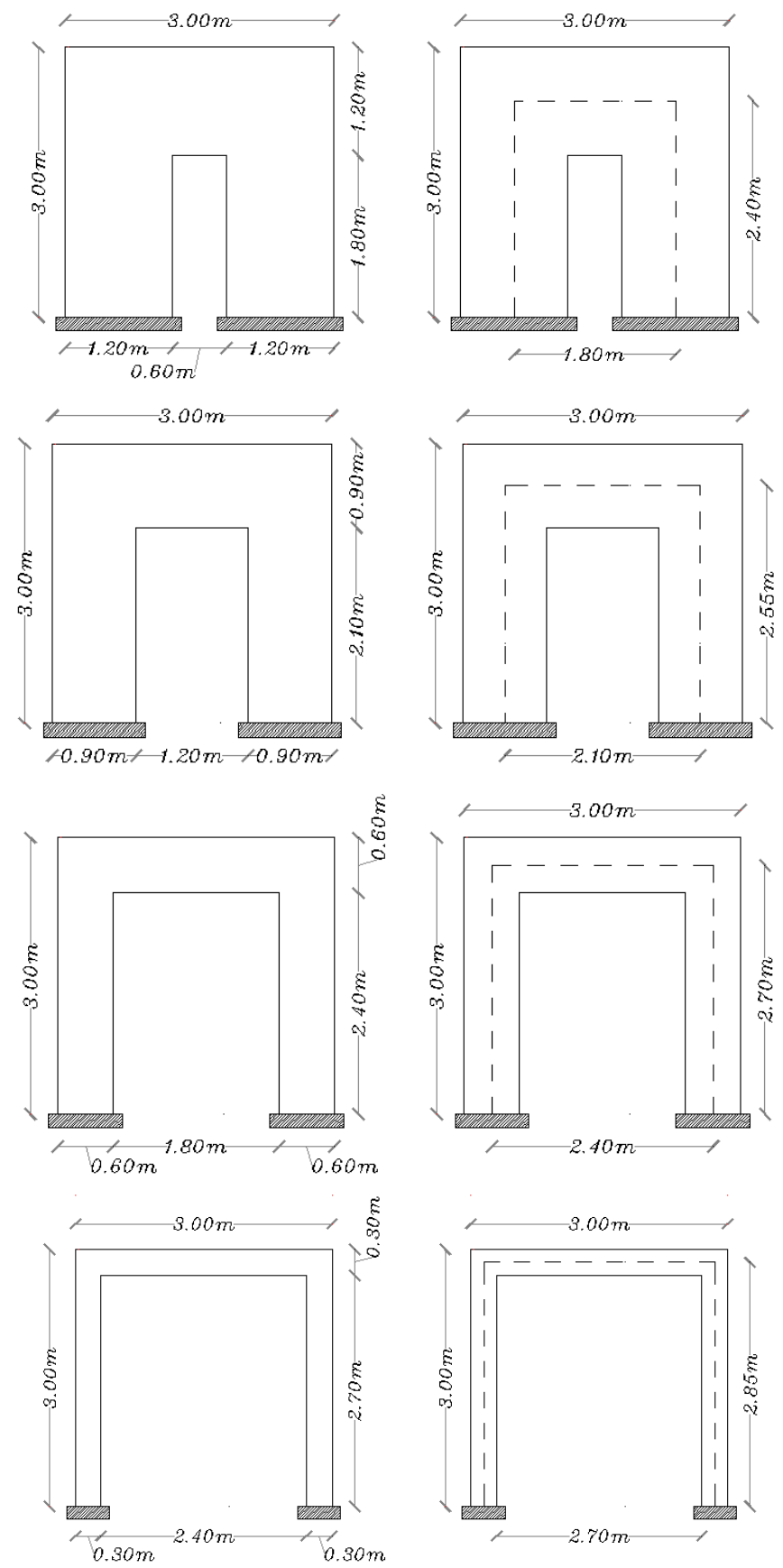

Fig. 7 C-D6,18/ C-D12,21/ C-D18-24/ C-D24-27 solid wall and its equivalent frame model from left to right respectively

The results of the total lateral deflection $(\Delta)$ from 2D wall, total deflection from 1D beam equivalent frame model, both flexural deflection $(\Delta \mathrm{f})$ and shear deflection $(\Delta \mathrm{s})$ from the equivalent frame model, the lateral stiffness (K), and the stiffness ratio (RS) are tabulated in Table 3 and they are drawn in Fig. 8. 
The reason why both shear and flexural deflection are gutted from the equivalent frame model is because SAP2000 doesn't clarify the contribution of both shear and flexure deformation and gives only the total deflection of the $2 \mathrm{D}$ area element.

Table 3. Results of door opening models with a $3 \times 3 \mathrm{~m}$ wall from SAP2000

\begin{tabular}{|c|c|c|c|c|c|c|c|}
\hline $\begin{array}{c}\text { Model } \\
\text { number }\end{array}$ & $\begin{array}{c}\text { Opening } \\
\text { size } \\
\text { (m) }\end{array}$ & $\begin{array}{c}\Delta \text { 2D area } \\
\text { total } \\
(\mathrm{mm})\end{array}$ & $\begin{array}{c}\Delta \text { 1D beam } \\
\text { total } \\
(\mathrm{mm})\end{array}$ & $\begin{array}{c}\Delta_{\mathrm{s}} \\
(\mathrm{mm})\end{array}$ & $\begin{array}{c}\Delta_{\mathrm{f}} \\
(\mathrm{mm})\end{array}$ & $\begin{array}{c}\text { Stiffness, } \\
\mathrm{K} \\
\left(10^{4}\right. \\
\mathbf{k N} / \mathbf{m}) \\
\end{array}$ & $\begin{array}{c}\text { Stiffness } \\
\text { Ratio, Rs } \\
\text { (\%) }\end{array}$ \\
\hline C-D6,18 & $0.6 \times 1.8$ & 2.37 & 2.37 & 0.95 & 1.42 & 42.19 & 62.02 \\
\hline C-D12,21 & $1.2 \times 2.1$ & 4.75 & 4.94 & 1.24 & 3.70 & 21.05 & 30.95 \\
\hline C-D18,24 & $1.8 \times 2.4$ & 15.72 & 16.18 & 1.98 & 14.20 & 6.36 & 9.35 \\
\hline C-D24,27 & $2.4 \times 2.7$ & 135.02 & 136.30 & 4.13 & 132.17 & 0.74 & 1.09 \\
\hline
\end{tabular}

\subsection{Discussion of Results}

Fig. 8 shows the relationship between $\mathrm{R}_{\mathrm{s}}$ and $\mathrm{R}_{\mathrm{o}}$, where it has the same trend in the case of window opening. Increasing the size of opening will decrease the stiffness of the wall as expected and as shown previously. When the door opening ratio is $17 \%$ from the total wall area, the wall will lose almost $50 \%$ of its stiffness and this ratio is the same as in the case of window opening. The typical door opening of $1.00 \times 2.00 \mathrm{~m}$ which is commonly used in practice and represents $22.22 \%$ of RO in a wall of $3.00 \times 3.00 \mathrm{~m}$ will result in a loss of the stiffness of this wall to about $60 \%$.

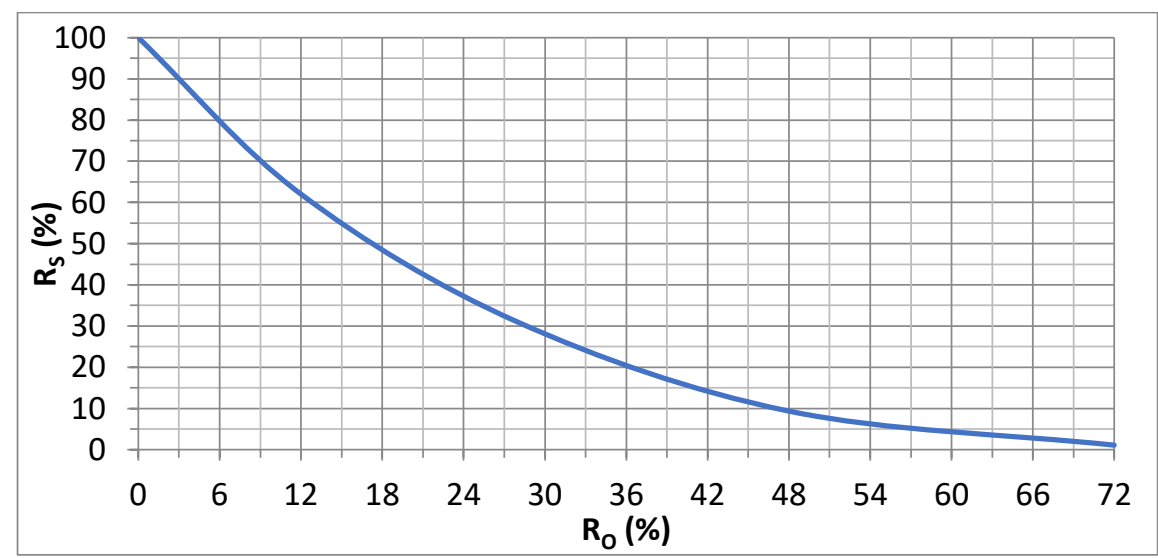

Fig. 8 Door opening ratio versus stiffness ratio of $3 \times 3 \mathrm{~m}$ wall

Fig.9 shows the contributions of both shear and flexural deflections from the total deflection results drawn by using results listed in Table 3. Assuming a 5\% of shear deformation contribution to be considered negligible, the minimum door opening ratio that converts the solid wall to a frame shall be equal to $65 \%$ from the total wall area, and from Fig. 8 this ratio makes Rs of the wall equal to $2.90 \%$. 


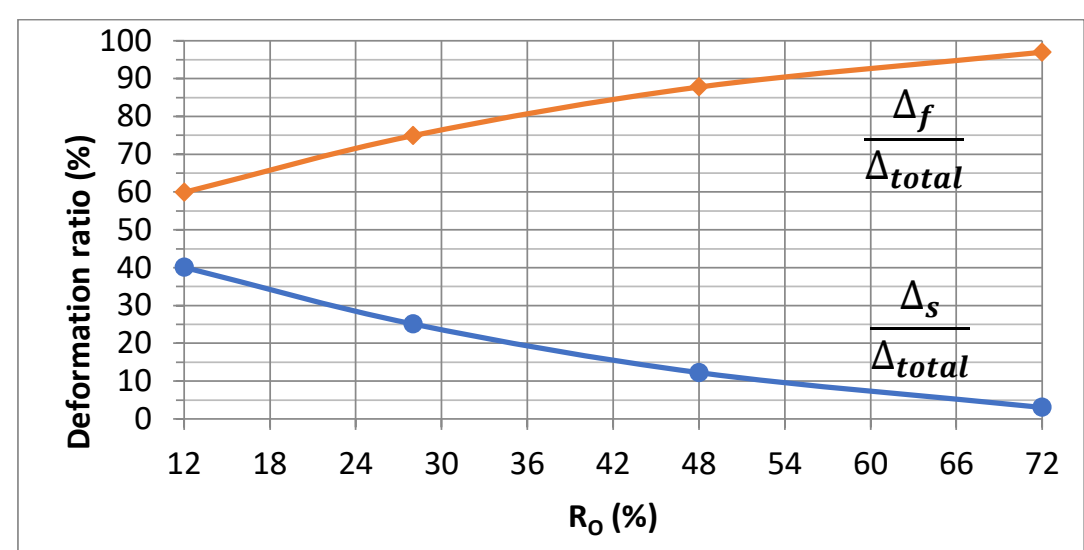

Fig. 9 Relative contribution of shear and flexure deformation to total wall with door opening deformation in a $3 \times 3 \mathrm{~m}$ wall

\section{Conclusions}

In this study, the modeling and behavior of individual concrete shear walls with openings are discussed. These openings are both central squared windows and door openings. A matrix of parameters that is expected to have an effect on the lateral stiffness of the wall is searched. This matrix includes a wall aspect ratio (H/B), opening type, and opening ratio RO. The effect of opening on the lateral deflection of the wall is discussed in both conditions: in central opening and in multiple central openings with different wall heights. The main founds and conclusions can be summarized as the following:

- The opening size plays major role on the lateral displacement and stiffness of reinforced concrete shear walls.

- Increasing the size of opening at shear walls will increase the lateral displacement, and thus reduce the lateral stiffness of structure.

- It is found that the maximum window opening at concrete shear walls that could be neglected in modeling, due to simplification, will be up to $3 \%$ from the total wall area when $5 \%$ of the stiffness ratio RS reduction can be accepted.

- It is concluded that, in multiple wall aspect ratios, $\mathrm{H} / \mathrm{B}$, with central window opening in concrete shear walls, it is noticed that increasing the wall aspect ratio $\mathrm{H} / \mathrm{B}$ will decrease the effect of openings in the lateral deflection and stiffness of the concrete shear wall and this is because the deflection mode of the wall becomes dominated by flexure.

- It is found that, $65 \%$ of the door opening will convert a solid wall to a frame in it is behavior when $5 \%$ difference due to shear deformation contribution may be considered negligible.

- It is found that, a typical door in a common practice with dimensions of $1.00 \times 2.00 \mathrm{~m}$ decreases a $3 \times 3 \mathrm{~m}$ solid wall stiffness by $60 \%$.

\section{References}

[1] Taranath BS. Reinforced Concrete Design of Tall Buildings. CRC Press. Taylor \& Francis Group, 2010. https://doi.org/10.1201/9781439804810

[2]Aghayari R, Ashrafy M, Roudsari M. Estimation of the Base Shear and Fundamental Period of Low-Rise Reinforced Concrete Coupled Shear Wall Structures. Asian Journal of Civil Engineering, 2017; 18 (7). 
[3] Ruchi S, Jignesh A. Effects of opening in shear walls of 30- storey building. JOURNAL OF MATERIALS AND ENGINEERING STRUCTURES, 2015;2: 44-55.

[4] Hsiao KJ. Hand- Calculated Procedure for Rigidity Computation of Shear Walls with Openings. ASCE Journal of Structural Engineering, 2014; 19(4). https://doi.org/10.1061/(ASCE)SC.1943-5576.0000210

[5] Harini AT, Kumar GS. Behavior of R.C. Shear Wall with Staggered Openings under Seismic Loads. International Journal for Research in Emerging Science and Technology, 2014; 2(3).

[6] Sharmin RC, Rahman MA, Islam MJ, Das AK. Effect of Openings in Shear Wall on Seismic Response of Structure. International Journal of computer applications, 2012; 59 (1): 10-13. https://doi.org/10.5120/9511-3901

[7] Abbas MH. Analysis of Shear Wall with Openings using Brick Element. European Journal of Scientific Research, 2011;51 (3): 359-371.

[8] Neuenhofer, A. Lateral Stiffness of Shear Walls with Openings. ASCE Journal of Structural Engineering, 2006; $132 \quad$ (11): $1846-1851$. https://doi.org/10.1061/(ASCE)0733-9445(2006)132:11(1846)

[9] Kim HS, Lee DG. Analysis of shear wall with openings using super elements, Engineering Structures, 2003; 25: 981-991. https://doi.org/10.1016/S0141-0296(03)00041-5

[10] Balkaya C, Kalkan E. Estimation of Fundamental Period of Shear-Wall Dominate Building Structures. The Journal of Earthquake Engineering and Structural Dynamics, 2003; 32 (7): 985-998. https://doi.org/10.1002/eqe.258

[11] J'aidi YT. Rigidity of Reinforced Concrete Shear Walls and Effect of Openings. Master thesis. An-Najah National University, 2002.

[12] Qaqish S,Daqqaq F. Effect of horizontal forces on shear walls with small openings. Technical Services and Studies-University of Jordan. Jordan, 2000.

[13] Mays GC, Hetherington JG, Rose TA. Resistance-Deflection Functions for Concrete Wall Panels with Openings. Journal of Structural Engineering, 1998; 124 (5): 579-587. https://doi.org/10.1061/(ASCE)0733-9445(1998)124:5(579)

[14] Yanez FV, Park R, Paulay T. Seismic behavior of walls with irregular openings. Earthquake Engineering. Tenth World Conference, Balkema, Rotterdam, 1992.

[15] Lin CY, Kuo CL. Behavior of shear wall with openings. Proceedings of Ninth world Conference on Earthquake Engineering. Tokyo-Kyoto, Japan, IV:535-540, 1988.

[16] Ambrose J, Vergun D. Simplified Building Design for Wind and Earthquake Forces. Third Edition, John Willey \& Sons INC, 1995. 